\title{
Removal of Chromium from Aqueous Solution Using Hybrid Membrane of Chitosan and Silicon Dioxide
}

\author{
Yanling Deng ${ }^{1}$, Naoki Kano ${ }^{2}$ and Hiroshi Imaizumi ${ }^{2}$ \\ 1. Graduate School of science and Technology, Niigata University, Niigata 950-2181, Japan \\ 2. Department of Chemistry and Chemical Engineering, Faculty of Engineering, Niigata University, Niigata 950-2181, Japan
}

\begin{abstract}
Adsorption experiment from aqueous solutions containing known amount of chromium (Cr) using hybrid membrane of chitosan and silicon dioxide was explored to evaluate the efficiency of the membrane as sorbent for $\mathrm{Cr}(\mathrm{VI})$. Some variable parameters such as $\mathrm{pH}$, contact time and the dosage of the membrane were optimized. Adsorption isotherms of $\mathrm{Cr}(\mathrm{VI}) \mathrm{onto}$ the hybrid membrane were measured with varying initial concentrations under optimized condition. Furthermore, the sorption mechanism of $\mathrm{Cr}$ by the membrane was investigated by applying Langmuir and Freundlich isotherm equations to the data obtained. The surface morphology of the membrane was determined by SEM (scanning electron microscope) for material characterization. The concentrations of $\mathrm{Cr}$ in solution are determined by ICP-MS (inductively coupled plasma mass spectrometry). Hybrid membrane of chitosan and silicon dioxide can be an efficient sorbent for $\mathrm{Cr}(\mathrm{VI})$.
\end{abstract}

Key words: Hybrid membrane, chitosan, silicon dioxide, adsorption isotherms, kinetics.

\section{Introduction}

With the rapid growth of mankind, society, science and technology, the environmental disorder with a big pollution problem has become one of the most important issues in the past half century [1]. The heavy metal contamination is a serious problem to the environment [2], and has become a challenge for life on earth because of the anthropogenic activities. The use of chromium and its compounds in several industrial processes (automobile manufacturing, production of steel and alloys, mining of chrome ore, plating and electroplating, etc.) leads to contamination of natural waters mainly due to improper disposal methods [3].

Particularly, $\mathrm{Cr}(\mathrm{VI})$ is the most toxic form, being carcinogenic and mutagenic to living organisms [4]. It leads to liver damage or pulmonary congestion, and causes skin irritation resulting in ulcer formation [5].

The typical mobile forms of $\mathrm{Cr}(\mathrm{VI})$ in natural

Corresponding author: Naoki Kano, Ph.D, associate professor, research field: environmental analysis and environmental reservation. environment are $\mathrm{CrO}_{4}{ }^{2-}, \mathrm{HCrO}_{4}{ }^{-}$and $\mathrm{H}_{2} \mathrm{CrO}_{4}$. The relative distribution of each species depends on the solution $\mathrm{pH}$, on the $\mathrm{Cr}(\mathrm{VI})$ concentration and on the redox potential [6]. They can be taken up by plants and easily be leached out into the deeper soil layers, leading to ground and surface water pollution, because of its high toxicity and its water solubility in the full $\mathrm{pH}$ range. $\mathrm{Cr}(\mathrm{VI})$ must be substantially removed from the wastewater before being discharged into the aquatic system.

Different technologies for the removal of $\mathrm{Cr}(\mathrm{VI})$ are available such as chemical precipitation, coagulation, ion exchange, membrane technologies,adsorption. Adsorption has been proved as one of the most efficient methods for the removal of heavy metals from aqueous media [7]. The major advantages of biosorption are its high effectiveness, easy operation, no two pollutions, and the use of inexpensive biosorbents.

Chitosan has proven to be very efficient as biosorbent for the recovery of several toxic metals such as mercury $(\mathrm{Hg})$, uranium (U), molybdenum (Mo), vanadium (V) and platinum (Pt) [8-10]. 
Chitosan is produced by the alkaline deacetylation of chitin, which is the most abundant biopolymer in nature originated from cellulose. Chitosan is a polymer that can be obtained from the shells of seafood such as prawns, crabs, and lobsters [11]. The biopolymer is characterized by its high percentage of nitrogen, existed in the form of amine groups that are responsible for metal ion binding through chelation mechanisms [12].

Silica gels are low-density solids, consisting of silicon oxide. The study of silica gels has attained considerable attention due to open mesoporous structure, high surface area, large pore volume and good performance as effective adsorbents [13]. At present, an interest has grown in the field of organic and in organic hybrid materials. The silica gels doped with some organic or inorganic material possess a number of novel properties [14, 15].

Due to above-mentioned reason, novel materials were designed to combine the beneficial properties of silica gel and chitosan. In this paper, the adsorption potential of the hybrid material for $\mathrm{Cr}(\mathrm{VI})$ from aqueous solution was investigated under varying experimental conditions. Moreover, the surface morphology of the hybrid adsorbents was determined by SEM (scanning electron microscope) to characterize these materials.

\section{Experimental Sections}

\subsection{Materials and Reagents}

Chitosan was purchased from Tokyo Chemical Industry Co. (Tokyo, Japan). Cr(VI) standard solutions were prepared by diluting a standard solution (1,005 $\mathrm{mg} \cdot \mathrm{dm}^{-3} \mathrm{~K}_{2} \mathrm{Cr}_{2} \mathrm{O}_{7}$ solution), which was purchased from Kanto Chemical Co. Inc. All other chemical reagents were also purchased from Kanto Chemical Co., Inc. All reagents used were of analytical grade, and water $(>18.2 \mathrm{M} \Omega$ in electrical resistance) which was treated by an ultrapure water system (Advantec aquarius: RFU 424TA, Advantec Toyo, Japan) was employed throughout the work. The
pH meter (HORIBA UJXT 06T8, Japan) was used for the measurement of $\mathrm{pH}$.

The hybrid membrane of chitosan and silicon dioxide were characterized by a SEM (JEOL, JSM-5800, Japan). The samples were placed on a microgrid of silicon, and transferred to the analytical chamber in the equipment, an ICP-MS (inductively coupled plasma mass spectrometry) instrument (Thermo Fisher Scientific X2, Japan) was used to determine the concentration of $\mathrm{Cr}(\mathrm{VI})$.

\subsection{Prepared Hybrid Membrane of Chitosan and Silicon Dioxide}

The solution of chitosan $(3 \%, w / v)$ was prepared by dissolving $3 \mathrm{~g}$ of chitosan in $100 \mathrm{~mL}$ of $0.2 \mathrm{~mol} \cdot \mathrm{dm}^{-3}$ acetic acid solution. Silica sols (which was prepared by dissolving $2 \mathrm{~mL}$ of 3-Aminopropyltriethoxysilane in $100 \mathrm{~mL}$ ethanol) was added into the solution of chitosan $(3 \%, \mathrm{w} / \mathrm{v})$ at $25{ }^{\circ} \mathrm{C}$ and was stirred for $24 \mathrm{~h}$. The hybrid membrane of chitosan and silicon dioxide was dried at $25^{\circ} \mathrm{C}$.

\subsection{Sorption Experiment of Cr(VI) Using Hybrid Membrane of Chitosan and Silicon Dioxide}

The adsorption capacities of $\mathrm{Cr}(\mathrm{VI})$ from aqueous solution using the hybrid membrane of chitosan and silicon dioxide were investigated by a batch method. Hybrid membrane of chitosan and silicon dioxide was thoroughly mixed with $50 \mathrm{~mL}$ of containing known concentrations of $\mathrm{Cr}(\mathrm{VI})$ in a $200 \mathrm{~mL}$ conical flask. According to the above-mentioned procedure, $\mathrm{Cr}(\mathrm{VI})$ were adsorbed at different $\mathrm{pH}$ values (1-7), contact time (20-120 $\mathrm{min})$ and sorbent dosage (0.05-0.3 $\left.\mathrm{g} \cdot \mathrm{dm}^{-3}\right)$. The $\mathrm{pH}$ of each solution was adjusted by using $0.1 \mathrm{~mol} \cdot \mathrm{dm}^{-3} \mathrm{NaOH}$ and $0.1 \mathrm{~mol} \cdot \mathrm{dm}^{-3} \mathrm{HCl}$. Adsorption isotherms of $\mathrm{Cr}(\mathrm{VI})$ onto hybrid membrane of chitosan and silicon dioxide were measured at varying initial $\mathrm{Cr}(\mathrm{VI})$ concentrations (10-50 ppm) under optimized conditions.

The adsorption capacities of $\mathrm{Cr}(\mathrm{VI})$ using hybrid membrane of chitosan and silicon dioxide was calculated using the Eq. (1): 


$$
q_{\mathrm{e}}=\frac{\left(C_{i}-C_{e}\right)}{m} \cdot V
$$

where $q_{e}$ is the adsorption capacities of $\mathrm{Cr}(\mathrm{VI})$ using hybrid membrane of chitosan and silicon dioxide at equilibrium $\left(\mathrm{mg} \cdot \mathrm{g}^{-1}\right), C_{i}$ and $C_{e}$ are the initial and equilibrium concentrations of $\mathrm{Cr}(\mathrm{VI})$ in a batch system respectively $\left(\mathrm{mg} \cdot \mathrm{dm}^{-3}\right), V$ is the volume of the solution $\left(\mathrm{dm}^{3}\right)$, and $m$ is the dry weight of hybrid membrane of chitosan and silicon dioxide $(\mathrm{g})$.

\subsection{Langmuir and Freundlich Isotherm Model}

Langmuir and Freundlich isotherms were modeled in order to evaluate the performance of adsorbents in adsorption processes by the relationship between the metal uptake $\left(q_{\mathrm{e}}\right)$ and the concentration of metal ion $\left(C_{\mathrm{e}}\right)$ at equilibrium. Langmuir and Freundlich adsorption isotherms can be expressed, respectively, the Langmuir equation is defined as Eq. (2):

$$
\frac{C_{e}}{q_{e}}=\frac{C_{e}}{q_{\max }}+\frac{1}{K_{L} q_{\max }}
$$

where, $C_{\mathrm{e}}$ and $q_{\mathrm{e}}$ are the concentration of $\mathrm{Cr}(\mathrm{VI})$ at equilibrium $\left(\mathrm{mg} \cdot \mathrm{L}^{-1}\right)$ and the amount of adsorption of $\mathrm{Cr}(\mathrm{VI})$ at equilibrium $\left(\mathrm{mg} \cdot \mathrm{g}^{-1}\right)$ respectively, $q_{\max }$ is the maximum adsorption capacity on the surface of hybrid membrane $\left(\mathrm{mg} \cdot \mathrm{g}^{-1}\right)$, and $K_{L}$ is the equilibrium adsorption constant $\left(\mathrm{L} \cdot \mathrm{mg}^{-1}\right)$. A plot of $\mathrm{C}_{e} / q_{e}$ versus $\mathrm{C}_{e}$ gives a straight line with slope of $1 / q_{\max }$, and intercept is $1 /\left(K_{L} q_{\max }\right)$.

The Freundlich isotherms equation is defined as Eq. (3):

$$
\log _{10} q_{e}=\log _{10} K_{F}+(1 / n) \log _{10} C_{e}
$$

where, $K_{F}$ is the adsorption capacity, $1 / n$ indicates the adsorption intensity. The plots of $q_{e}$ versus $C_{e}$ in $\log$ scale can be plotted to determine values of $1 / n$ and $K_{F}$ depicting the constants of Freundlich model.

\subsection{Kinetic Studies}

The study of sorption kinetics in aqueous solution is important because it provides deep understanding of the reaction pathways and the mechanism of sorption reactions [16]. In the present study, the mechanism of the adsorption process was investigated by fitting pseudo first-order and second-order reactions to the experimental data.

The pseudo-first order rate equation is generally expressed as follows Eq. (4):

$$
\ln \left(q_{e}-q_{t}\right)=\ln \left(q_{e}\right)-k_{1} t
$$

where, $q_{e}$ and $q_{t}$ are the adsorption capacities of $\mathrm{Cr}(\mathrm{VI})$ using the hybrid membrane at equilibrium and time $t$, respectively $\left(\mathrm{mol} \cdot \mathrm{g}^{-1}\right)$, and $k_{1}$ is the rate constant of the pseudo-first-order adsorption $\left(\mathrm{h}^{-1}\right)$.

The pseudo-second order rate equation is expressed as Eq. (5):

$$
\frac{t}{q_{t}}=\frac{1}{k q_{e}^{2}}+\frac{t}{q_{e}}
$$

where, $q_{e}$ and $q_{t}$ are the adsorption capacities of $\mathrm{Cr}(\mathrm{VI})$ using Theybrid membrane at equilibrium and time $t$, respectively $\left(\mathrm{mol} \cdot \mathrm{g}^{-1}\right)$, and $k$ is the rate constant of the pseudo-second-order adsorption $\left(\mathrm{g} \cdot \mathrm{mol}^{-1} \cdot \mathrm{h}^{-1}\right)$.

\section{Results and Discussion}

\subsection{Characteristics of Chitosan and Silicon Dioxide}

The SEM pictures of hybrid membrane of chitosan and silicon dioxide are shown in Fig. 1. It can be observed that hybrid adsorbents exist in the form of particles. Rashidova et al. [17] prepared the hybrid adsorbents of chitosan and silica, and proposed the theory of chitosan and silica network where chitosan moieties were combined through silica groups via both ionic and covalent bonds. The hybrid adsorbents synthesized in this work also may contain free amino groups that are responsible for metal ion binding through chelation mechanisms.

\subsection{Effect of $p H$}

For obtaining the optimum conditions regarding the adsorption of $\mathrm{Cr}(\mathrm{VI})$ onto the hybrid membrane of chitosan and silicon dioxide, the effects of $\mathrm{pH}$ on the removal of $\mathrm{Cr}(\mathrm{VI})$ were investigated under the fixed 


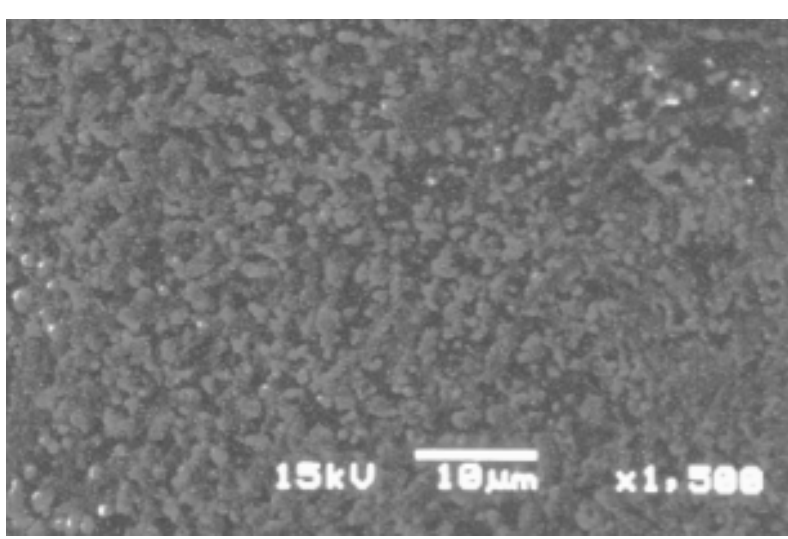

Fig. 1 SEM pictures of hybrid membrane of chitosan and silicon dioxide.

condition of initial $\mathrm{Cr}(\mathrm{VI})$ concentration (50 ppm), the contact time $(100 \mathrm{~min})$ and the dosage of the adsorbent $\left(0.2 \mathrm{~g} \cdot \mathrm{dm}^{-3}\right)$.

The results for $\mathrm{pH}$ dependency are shown in Fig. 2. The removal of $\mathrm{Cr}(\mathrm{VI})$ more than $76 \%$ was observed at $\mathrm{pH}$ 3. It is well known that $\mathrm{pH}$ influences significantly in the adsorption processes by affecting both the protonation of the surface groups and the degree of the ionization of the adsorbates [18]. The surface of the adsorbent will be positively charged at lower $\mathrm{pH}$, and it will not favor the adsorption of positively charged ions. Then it will favor the adsorption of $\mathrm{Cr}(\mathrm{VI})$ in the anionic form as $\mathrm{HCrO}_{4}{ }^{-}$ $[19,20]$.

As shown in Fig. 3 taken from Irgolic et al. [21], the dominant form of $\mathrm{Cr}(\mathrm{VI})$ exists as hydrogen chromate anions $\left(\mathrm{HCrO}_{4}{ }^{-}\right)$between $\mathrm{pH} 2$ and 6.5 . With the increase of $\mathrm{pH}$, the dominant species will change from $\mathrm{HCrO}_{4}{ }^{-}$to other form $\mathrm{CrO}_{4}{ }^{2-}$ [22]. Then, $\mathrm{pH} 3$ was selected as the optimal $\mathrm{pH}$ for further work.

\subsection{Effect of Contact Time}

The effect of contact time on the adsorption capacity of $\mathrm{Cr}(\mathrm{VI})$ using hybrid membrane of chitosan and silicon dioxide is studied at optimal $\mathrm{pH}$ under the initial $\mathrm{Cr}(\mathrm{VI})$ concentration of $50 \mathrm{ppm}$ and the hybrid membrane dosage of $0.2 \mathrm{~g} \cdot \mathrm{dm}^{-3}$. The removal rate reached $76.4 \%$ as shown in Fig. 4. The adsorption capacity of hybrid membrane for $\mathrm{Cr}(\mathrm{VI})$ reached adsorption equilibrium at $80 \mathrm{~min}$, and after that there

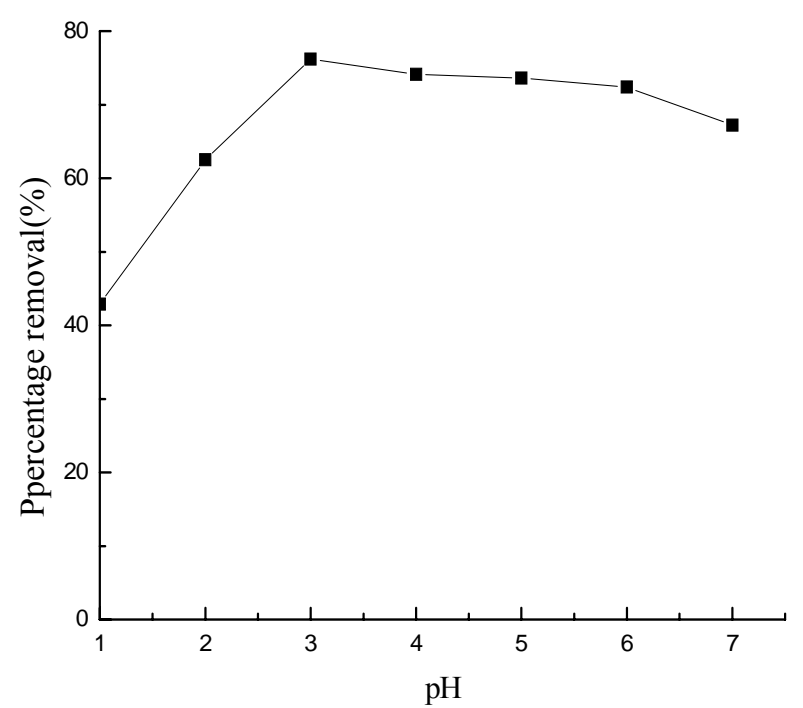

Fig. 2 Effect of $\mathrm{pH}$ on percent removal of $\mathrm{Cr}(\mathrm{VI})$ using hybrid membrane of chitosan and silicon dioxide.

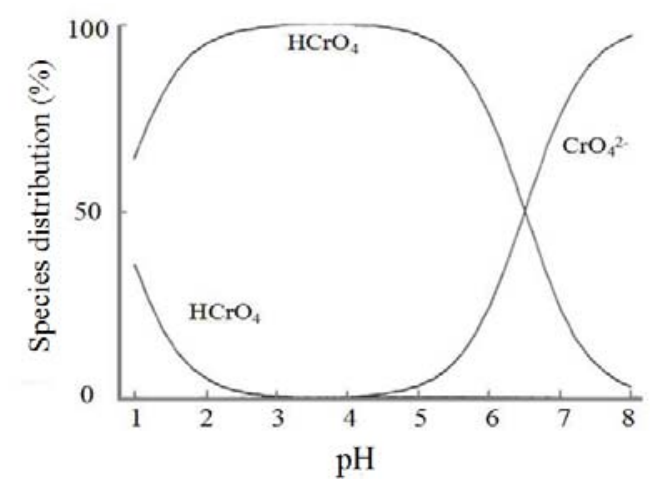

Fig. 3 Species distribution curves of $\operatorname{Cr}(\mathrm{VI})$ in environmental water.

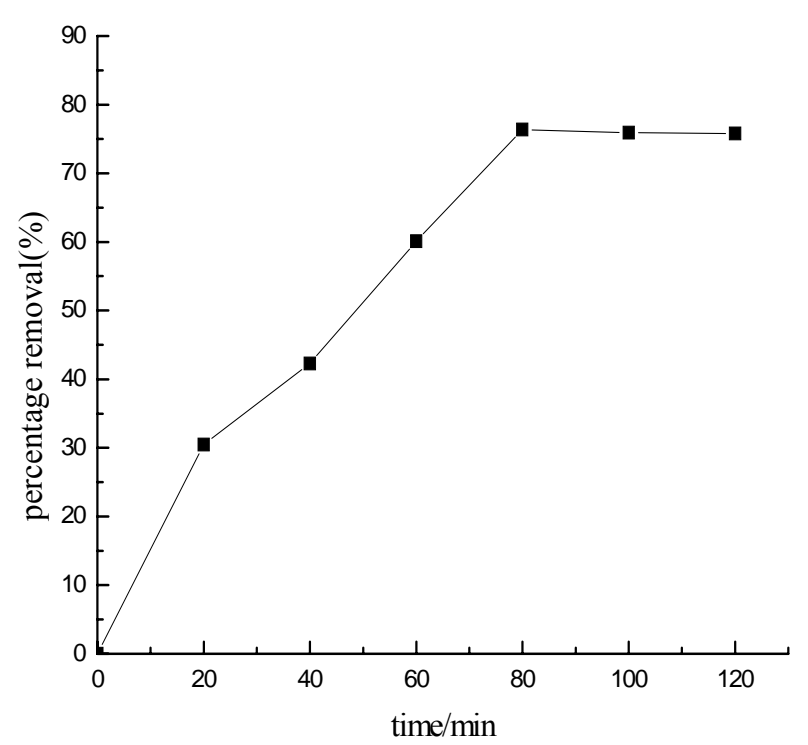

Fig. 4 Effect of contact time on percent removal of $\mathrm{Cr}(\mathrm{VI})$ using hybrid membrane of chitosan and silicon dioxide. 
are a slight decrease due to the swelling properties of hybrid membrane absorbent. Therefore, the optimized contact time was selected for $80 \mathrm{~min}$.

\subsection{Effect of Hybrid Membrane Dosage}

Under optimized condition of $\mathrm{pH}$ and contact time, sorption behavior of the hybrid membrane at different dosages from $0.1 \mathrm{~g} \cdot \mathrm{dm}^{-3}$ to $0.3 \mathrm{~g} \cdot \mathrm{dm}^{-3}$ have been studied in $50 \mathrm{ppm}$ of $\mathrm{Cr}(\mathrm{VI})$ solution.

The results are shown in Fig. 5. The adsorption capacity of hybrid membrane for $\mathrm{Cr}(\mathrm{VI})$ reached adsorption equilibrium at $0.2 \mathrm{~g} \cdot \mathrm{dm}^{-3}$, and the removal rate reached $78.6 \%$. However, remarkable decrease is observed at a dosage more than $0.2 \mathrm{~g} \cdot \mathrm{dm}^{-3}$. Thus, 0.2 $\mathrm{g} \cdot \mathrm{dm}^{-3}$ was considered as optimized dose.

\subsection{Effect of Initial Concentration}

Study was carried out by varying initial concentrations from $10 \mathrm{ppm}$ to $50 \mathrm{ppm}$ under optimized conditions of $\mathrm{pH}$ (i.e., $\mathrm{pH} 3$ ), contact time (i.e., $80 \mathrm{~min}$ ) and sorbent dosage (i.e., $0.2 \mathrm{~g} \cdot \mathrm{dm}^{-3}$ ). There was a continuous increase in the uptake of $\mathrm{Cr}$ per gram of adsorbent up to the concentration of 40 $\mu \mathrm{g} \cdot \mathrm{dm}^{-3}$, but the uptake is almost constant at further higher concentrations (Fig. 6). The removal rate reached $78.7 \%$. Then, $40 \mathrm{ppm}$ was considered as optimum initial concentration for $\mathrm{Cr}(\mathrm{VI})$.

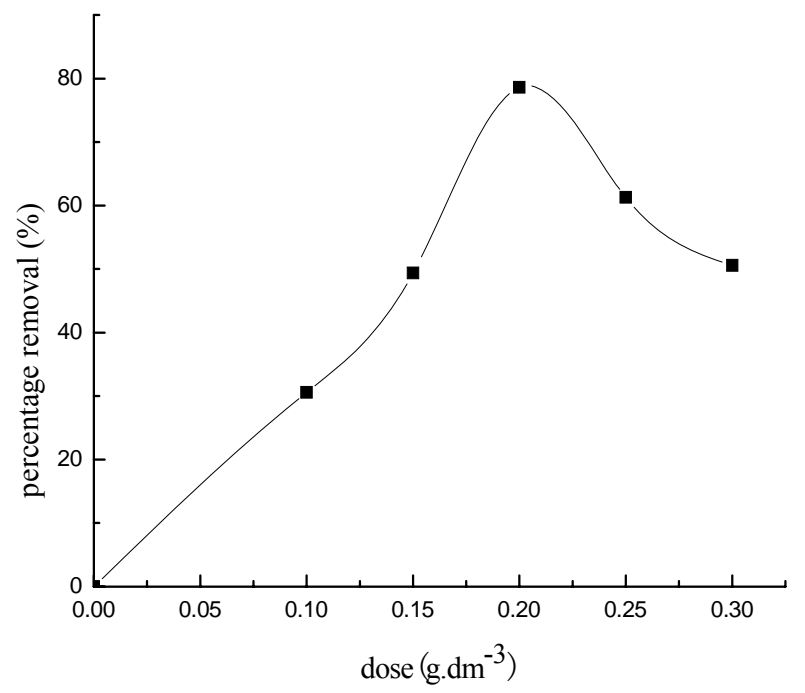

Fig. 5 Effect of dose on percent removal of $\mathrm{Cr}(\mathrm{VI})$ using hybrid membrane of chitosan and silicon dioxide.

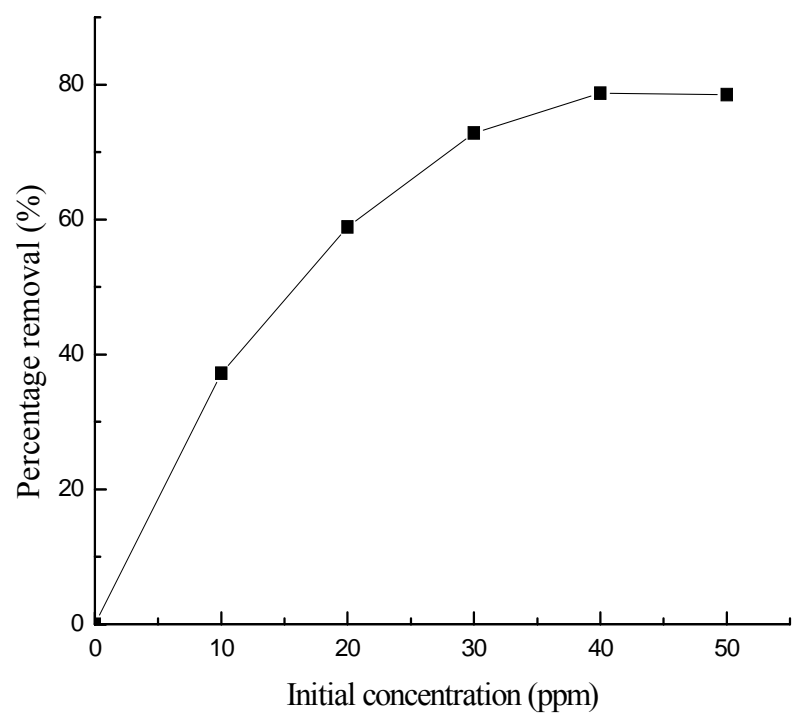

Fig. 6 Effect of initial concentration on percent removal of Cr(VI) using hybrid membrane of chitosan and silicon dioxide.

\subsection{Adsorption Isotherms}

Adsorption isotherms are commonly used to reflect the performance of adsorbents in adsorption processes [23]. Langmuir and Freundlich isotherms were used in this work to evaluate the performance of adsorbents by the relationship between the metal uptake $\left(q_{\mathrm{e}}\right)$ and the concentration of metal ion $\left(C_{\mathrm{e}}\right)$ at equilibrium. The adsorption data obtained for $\mathrm{Cr}(\mathrm{VI})$ using hybrid membrane of chitosan and silicon dioxide were analyzed by Langmuir (Fig. 7) and Freundlich equations (Fig. 8). The correlation coefficient $\left(R^{2}\right)$ of these isotherms for $\mathrm{Cr}(\mathrm{VI})$ on the hybrid membrane is shown in Table 1 along with other relevant parameters. From Table 1, it is found that $R^{2}$ value for $\mathrm{Cr}(\mathrm{VI})$ is comparatively large, and favorable adsorption of $\mathrm{Cr}(\mathrm{VI})$ on the hybrid membrane was presented. Particularly, $R^{2}$ values in Langmuir isotherm are larger than that in Freundlich isotherm.

This result suggests that the adsorption of $\mathrm{Cr}$ on hybrid membrane of chitosan and silicon dioxide mainly occurred by monolayer reaction.

\subsection{Kinetic Studies}

Kinetic models were tested in this study for the sorption of $\mathrm{Cr}(\mathrm{VI})$ onto the hybrid membrane of 


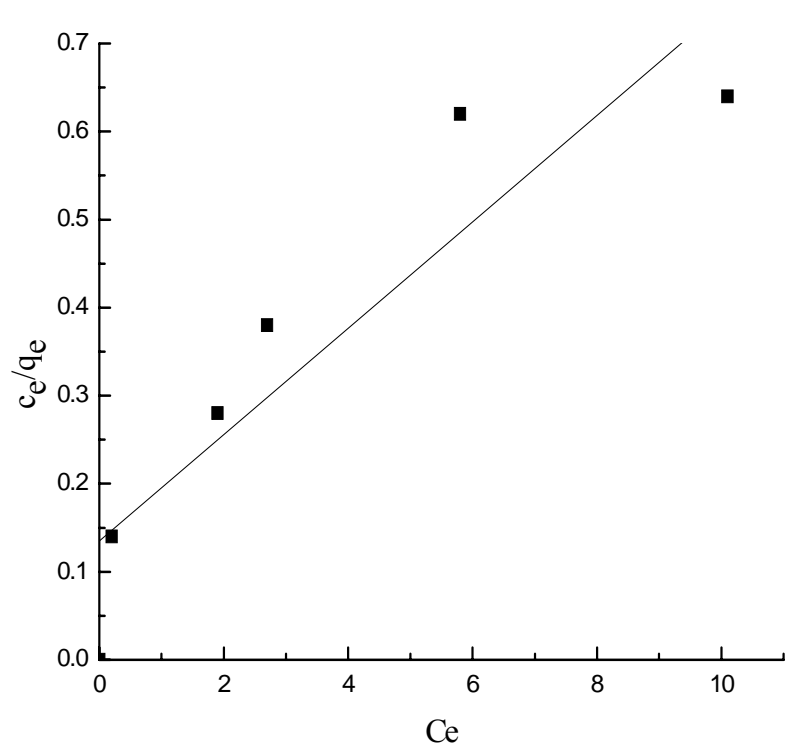

Fig. 7 Langmuir isotherm of $\mathrm{Cr}(\mathrm{VI})$ adsorption onto hybrid membrane of chitosan and Silicon dioxide.

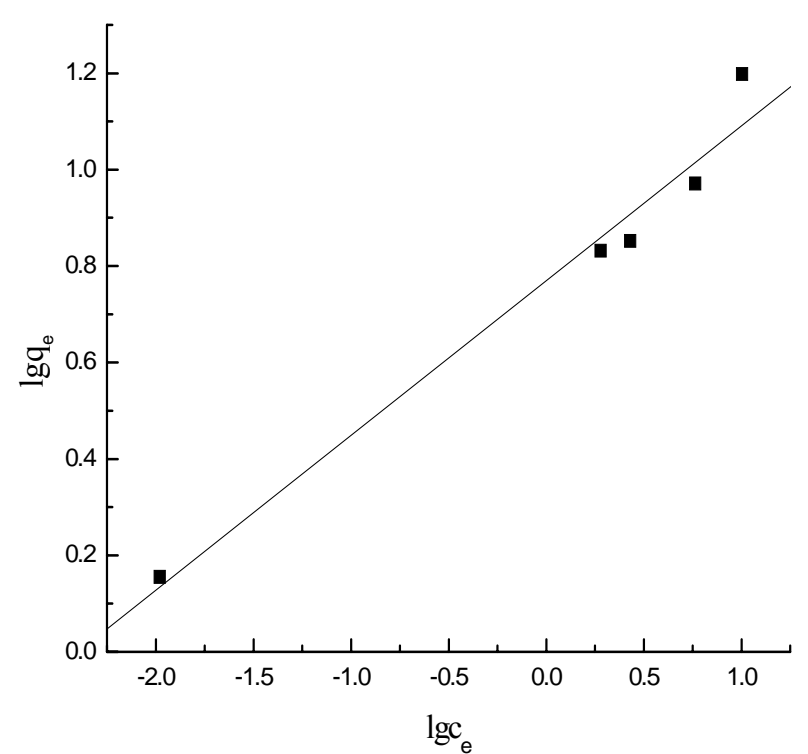

Fig. 8 Freundlich isotherm of $\mathrm{Cr}(\mathrm{VI})$ adsorption onto hybrid membrane of chitosan and Silicon dioxide.

Table 1 Coefficient of Langmuir and Freundlich isotherms for $\operatorname{Cr}(\mathrm{VI})$ using hybrid membrane of chitosan and silicon dioxide.

\begin{tabular}{lllllll}
\hline & \multicolumn{5}{c}{ Langmuir isotherm } & \multicolumn{2}{c}{ Freundlich isotherm } \\
\cline { 2 - 7 } & $\begin{array}{l}q_{\max } \\
{\left[\mathrm{mg} \cdot \mathrm{g}^{-1}\right]}\end{array}$ & $\begin{array}{l}K_{L} \\
{\left[\mathrm{dm}^{-3} \cdot \mathrm{mg}^{-1}\right]}\end{array}$ & $R^{2}$ & $\begin{array}{l}K_{F} \\
{\left[\left(\mathrm{mg} \cdot \mathrm{g}^{-1}\right)\right.}\end{array}$ & $1 / \mathrm{n}$ & $R^{2}$ \\
Hybrid membrane & $2.1 \mathrm{E}+02$ & $1.32-01$ & 0.985 & 3.21 & 0.78 & 0.912 \\
\hline
\end{tabular}

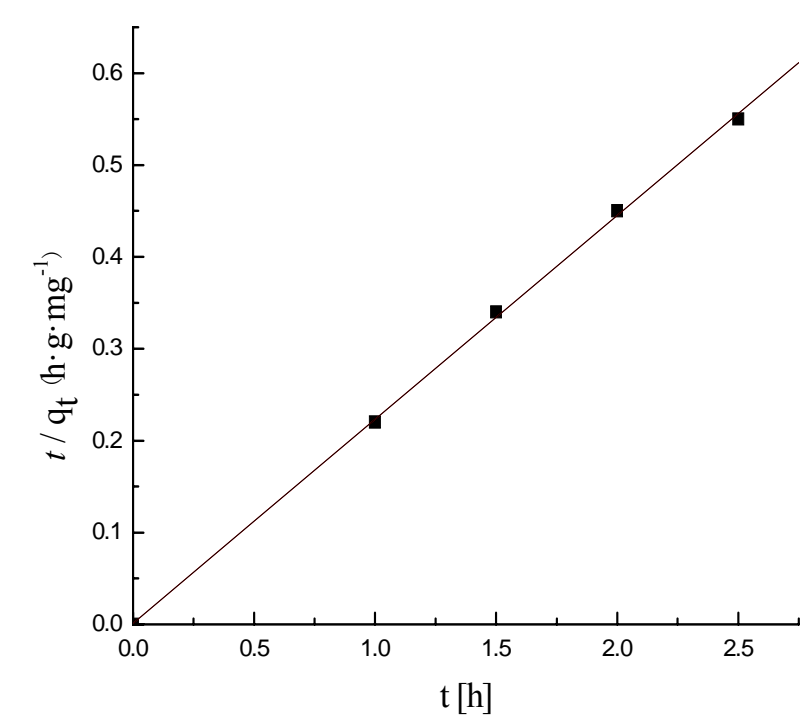

Fig. 9 The pseudo second-order kinetic model on hybrid membrane of chitosan and silicon dioxide.

Table 2 The pseudo second-order kinetic coefficient for Cr(VI) using hybrid membrane of chitosan and silicon dioxide.

\begin{tabular}{llll}
\hline & $\begin{array}{l}q_{\mathrm{e}} \\
\left(\mathrm{mg} \cdot \mathrm{g}^{-1}\right)\end{array}$ & $\begin{array}{l}k \\
\left(\mathrm{~g} \cdot \mathrm{mol}^{-1} \cdot \mathrm{h}^{-1}\right)\end{array}$ & $R$ \\
\hline $\mathrm{Cr}(\mathrm{VI})$ & 0.106 & $1.17 \times 10^{-3}$ & 0.996 \\
\hline
\end{tabular}

chitosan and silicon dioxide under the optimized experimental conditions. It is observed that the rates of adsorption were found to conform to pseudo-second order equation than pseudo first-order equation in this work. The results for kinetic studies are shown in Fig. 9. Based on the data in Fig. 9, the pseudo second-order kinetic coefficients for $\mathrm{Cr}(\mathrm{VI})$ by the hybrid membrane are estimated (Table 2). The rate constant of second-order equation $(k)$ diffusion is 1.17 $\times 10^{-2} \mathrm{~g} \cdot \mathrm{mol}^{-1} \cdot \mathrm{h}^{-1}$ for $\mathrm{Cr}(\mathrm{VI})$. The correlation coefficients $\left(R^{2}\right)$ were 0.996 for $\mathrm{Cr}(\mathrm{VI})$ adsorption on the hybrid membrane.

\section{Conclusions}

The efficiency of hybrid membrane of chitosan and silicon dioxide as an adsorbent for $\mathrm{Cr}(\mathrm{VI})$ was investigated. According to these studies, the following conclusions were clarified:

(1) The optimal conditions of adsorption $\mathrm{Cr}$ (VI) using hybrid membrane of chitosan and silicon 
dioxide are determined. The optimal $\mathrm{pH}$ is $\mathrm{pH} 3$; the optimal contact time is $80 \mathrm{~min}$; the optimal dosage is $2.0 \mathrm{~g} \cdot \mathrm{dm}^{-3}$ and $40 \mathrm{ppm}$ was considered as optimum initial concentration.

(2) The hybrid membrane exhibited high adsorption capacity for $\mathrm{Cr}(\mathrm{VI})$. The removal of $\mathrm{Cr}(\mathrm{VI})$ was 78.7\% under this optimal experimental conditions.

(3) $\mathrm{Cr}(\mathrm{VI})$ adsorption using hybrid membrane of chitosan and silicon dioxide conforms to the Langmuir isotherm adsorption equation, and the correlation coefficients are more than 0.98. The maximum adsorption capacity of $\mathrm{Cr}(\mathrm{VI})$ calculated by Langmuir model was $2.1 \times 10^{-2} \mathrm{mg} \cdot \mathrm{g}^{-1}$.

(4) The best fit was obtained with a pseudo-second order kinetic model while investigating the adsorption kinetics.

According to the above conclusions, the results show that it was quantitatively clarified to some extent that hybrid membrane of chitosan and silicon dioxide can be an efficient sorbent for $\mathrm{Cr}(\mathrm{VI})$, which provides important information for the management of water pollution problems.

\section{Acknowledgements}

The present work was partially supported by a Grant-in-Aid for Scientific Research (Research Program (C), No. 16K00599) of the Japan Society for the Promotion of Science. This research was also supported by a fund for the promotion of Nigata University KAAB Projects from the Ministry of Education, Culture, Sports, Science and Technology, Japan.

The authors are also grateful to Mr. M. Ohizumi of Office for Environment and Safety in Niigata University, Mr. T. Hatamachi, Mr. T. Nomoto and Prof. T. Tanaka and of Fac. of Eng. in Niigata University for permitting the use of ICP-MS, Surface Area Analyzer and SEM for giving helpful advice in measurement.

\section{References}

[1] Chih, H. H., Chang, K. P., Ou, H. D., and Chiang, Y. C.,
2011. "Adsorption of Cationic Dyes onto Mesoporous Silica." Microporous and Mesoporous Materials 141: 102-9.

[2] Junior, O. K., Gurgel, L. V. A., and Freitas, R. P. 2009. "Adsorption of $\mathrm{Cu}(\mathrm{II}), \mathrm{Cd}(\mathrm{II})$, and $\mathrm{Pb}(\mathrm{II})$ from Aqueous Single Metal Solutions by Mercerized Cellulose and Mercerized Sugarcane Bagasse Chemically Modified with EDTA Dianhydride.” Carbohydrate Polymers 77 (3): 643-50.

[3] Sarin, V., Sarvinder, S. T., and Pant, K. K. 2006. "Thermodynamic and Breakthrough Column Studies for the Selective Sorption of Chromium from Industrial Effluent on Activated Eucalyptus Bark." Bioresour. Techonol. 97: 1986-93.

[4] Partensky, D. B., Wilbourn, C. J., and Rice, J. M. 1998. "An IARC Evaluation of Polychlorinated Dibenzo-p-dioxins and Polychlorinated Dibenzofurans as Risk Factors in Human Carcinogenesis.” Environ Health Perspect 106: 755-60.

[5] Cieslak, G. M. 1996. "Toxic and Mutagenic Effects of Chromium (VI).” Polyhedron 15: 3667-918.

[6] Fendorf, S. E. 1995 "Surface Reactions of Chromium in Soils and Waters." Geoderma 67: 55-71.

[7] Kotas, J., and Stasicka, Z. 2000. "Chromium Occurrence in the Environment and Methods of Its Speciation." Environmental Pollution 107: 263-83.

[8] Inoue, K., Fingerman, M., Nagabhushanam, R., and Thompson, M. 1998. "Application of Chitosan in Separation and Purification of Metals." Recent Advances in Marine Biotechnology, Environmental Marine Biotechnology 2: 63-97.

[9] Guibal, E., Larkin, A., Vincent, T., and Tobin, J. M. 1999. "Chitosan Sorbents for Platinum Sorption from Dilute Solutions." Ind. Eng. Chem. Res. 38 (10): 4011-22.

[10] Guzman, J., Saucedo, I., Revilla, J., Navarro, R., and Guibal, E. 2002. "Vanadium Interactions with Chitosan: Influence of Polymer Protonation and Metal Speciation." Langmuir 18 (5): 1567-73.

[11] Ng, J. C. Y., Cheung, W. H. and McKay, G. 2002. "Equilibrium Studies of the Sorption of $\mathrm{Cu}$ (II) Ions onto Chitosan." Journal of Colloid and Interface Science 255 (1): 64-74.

[12] Arrascue, M. L., Garcia, H. M., Horna, O., and Guibal, E. 2003. "Gold Sorption on Chitosan Derivatives." Hydrometallurgy 71 (1-2): 191-200.

[13] Fricke, J. A., and Springer, V. 1986. "Aerogels an Fascinating Class of High-Performance Porous Solids." Springer Proceedings in Physics 6: 2-19.

[14] Smirnova, I., Mamic, J., and Arlt, W. 2003 "Adsorption of Drugs on Silica Aerogels." Langmuir 19: 8521-5.

[15] Eveliina, R., Jolanta, K. W., Amit, B., and Mika, S. 2011. 


\section{Removal of Chromium from Aqueous Solution Using Hybrid Membrane of Chitosan and Silicon Dioxide}

"Heavy Metals Adsorption by Novel EDTA-modified Chitosan-Silica Hybrid Materials." Journal of Colloid and Interface Science 358: 261-7.

[16] Sag, Y., and Aktay, Y. 2002 "Kinetic Studies on Sorption of $\mathrm{Cr}(\mathrm{VI})$ and $\mathrm{Cu}(\mathrm{II})$ Ions by Chitin, Chitosan and Rhizopus Arrhizus." Biochemical Engineering Journal 12: 143-53.

[17] Rashidova, S. S., Shakarova, D. S., and Ruzimuradov, O. N. 2004. "Bionanocompositional Chitosan-silica Sorbent for Liquid Chromatography.” J. Chromatogr 800: 49-53.

[18] Eveliina, R., Jolanta, K. W., Amit, B., and Mika, S. 2011. "Heavy Metals Adsorption by Novel EDTA-modified Chitosan-Silica Hybrid Materials." Journal of Colloid and Interface Science 358: 261-7.

[19] Huang, C. P., and Bowers, A. R. 1978. "The Use of Activated Carbon for Chromium(VI) Removal." Water
Technol 10: 45-7.

[20] Khan, S. A., Rehman, R., and Khan, A. M. 1995. "Adsorption of Chromium(III), Chromium(VI) and Silver(I) on Bentonite." Waste Management 15 (4): 271-82.

[21] Irgolic, K. J., Greschonig, H., and Howard, A. G. 1999. Encyclopedia of Analytical Science. New York: Academic Press.

[22] Erhan, D., Mehmet, K., and Elif, S. 2004. "Adsorption Kinetics for the Removal of Chromium (VI) from Aqueous Solutions on the Activated Carbons Prepared from Agricultural Wastes." Water SA 30: 533-40.

[23] Copello, G. J., Varela, F., and Martinez, R. 2008. "Immobilized Chitosan as Biosorbent for the Removal of $\mathrm{Cd}(\mathrm{II}), \mathrm{Cr}(\mathrm{III})$ and $\mathrm{Cr}(\mathrm{VI})$ from Aqueous Solutions." Bioresource Technology 99: 6538-44. 